\title{
Digital gene expression analysis in the gills of Ruditapes philippinarum exposed to short- and long-term exposures of ammonia nitrogen
}

\author{
Ming Cong ${ }^{\mathrm{a}}$, Huifeng $\mathrm{Wu}^{\mathrm{a}, \mathrm{b}, *}$, Tengfei $\mathrm{Cao}^{\mathrm{c}}$, Jiasen $\mathrm{Lv}^{\mathrm{d}}$, Qing Wang ${ }^{\mathrm{a}}$, Chenglong $\mathrm{Ji}^{\mathrm{a}}$, Chenghua $\mathrm{Li}^{\mathrm{c}}$, \\ Jianmin Zhao ${ }^{\text {a,* }}$ \\ ${ }^{a}$ Key Laboratory of Coastal Environmental Processes and Ecological Remediation, Yantai Institute of Coastal Zone Research, Chinese Academy of Sciences, Yantai 264003, \\ PR China \\ ${ }^{\mathrm{b}}$ Laboratory for Marine Fisheries Science and Food Production Processes, Qingdao National Laboratory for Marine Science and Technology, Qingdao 266237, PR China \\ ${ }^{\mathrm{c}}$ School of Marine Sciences, Ningbo University, Ningbo 315211, PR China \\ d Biology School of Yantai University, Yantai 264005, PR China
}

\section{A R T I C L E I N F O}

\section{Keywords:}

Ruditapes philippinarum

Digital gene expression

Transcriptome

Ammonia nitrogen

Toxicity

\begin{abstract}
A B S T R A C T
Previous study revealed severe toxic effects of ammonia nitrogen on Ruditapes philippinarum including lysosomal instability, disturbed metabolic profiles, gill tissues with damaged structure, and variation of neurotransmitter concentrations. However, the underlying molecular mechanism was not fully understood yet. In the present study, digital gene expression technology (DGE) was applied to globally screen the key genes and pathways involved in the responses to short- and long-term exposures of ammonia nitrogen. Results of DGE analysis indicated that short-term duration of ammonia exposure affected pathways in Dorso-ventral axis formation, Notch signaling, thyroid hormone signaling and protein processing in endoplasmic reticulum. The long-term exposure led to DEGs significantly enriched in gap junction, immunity, signal and hormone transduction, as well as key substance metabolism pathways. Functional research of significantly changed DEGs suggested that the immunity of $R$. philippinarum was weakened heavily by toxic effects of ammonia nitrogen, as well as neurotransduction and metabolism of important substances. Taken together, the present study provides a molecular support for the previous results of the detrimental toxicity of ammonia exposure in $R$. philippinarum, further work will be performed to investigate the specific genes and their certain functions involved in ammonia toxicity to molluscs.
\end{abstract}

\section{Introduction}

Over the past decades, ammonia nitrogen has been a consistent pollutant in some marine fishery waters according to the annual reports on the state of Chinese marine environment. Of the two existing forms of ammonia in seawater, the un-ionized form $\left(\mathrm{NH}_{3}-\mathrm{N}\right)$ is more toxic than the ion form $\left(\mathrm{NH}_{4}{ }^{+}\right)$because of its capacity to diffuse through cell membranes (Emmerson et al., 1975). The un-ionized ammonia nitrogen (UIA) can induce many adverse effects in fishes, crustaceans and molluscs, including severe histological changes, neurological dysfunction, growth restriction, respiration impairment and fecundity decrement (Armstrong et al., 2012; Keppler, 2007; Maas et al., 2012; Randall and
Tsui, 2002; Smart, 1978). Although the invertebrates (such as molluscs) were generally found to be more tolerant to ammonia stress compared with the vertebrate (Arthur et al., 1987), toxicology studies indicated that ammonia nitrogen caused severe toxicity to the clams. Therefore, it is necessary to clarify the toxic mechanism of ammonia nitrogen on the molluscs in order to provide reliable data for practical treatment of reducing ammonia nitrogen pollution and environmental protection in shellfish aquaculture around the coastal area.

The toxic mechanism of ammonia has been studied more clearly in fishes than other aquatic organisms. It was found that ammonia depolarizes the neurons and activates the N-Methyl-D-aspartic acid (NMDA)type glutamate receptor, leading to subsequent cell apoptosis in the

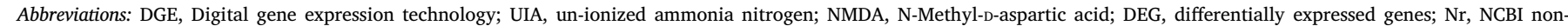

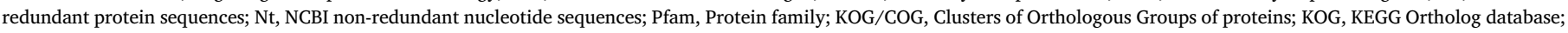

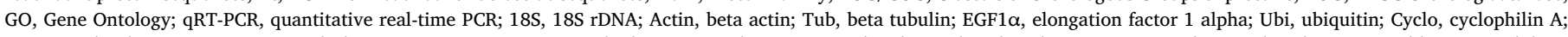

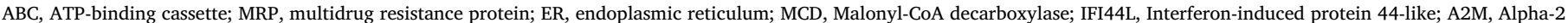
macroglobulin; EGF-like, epiderma-growth factor-like; GS, Glutamine synthetase; ABAT, 4-aminobutyrate aminotransferase

* Corresponding authors at: Key Laboratory of Coastal Environmental Processes and Ecological Remediation, Yantai Institute of Coastal Zone Research, Chinese Academy of Sciences, Yantai 264003, PR China.

E-mail addresses: hfwu@yic.ac.cn (H. Wu), jmzhao@yic.ac.cn (J. Zhao). 
brain by causing influxes of excessive $\mathrm{Ca}^{2+}$ and $\mathrm{K}^{+}$(Randall and Tsui, 2002). However, the related study on molluscs is still in a primary stage. Such toxic studies basically focus on the changes of survival rates, energy

allocation, cellular and immune parameters after ammonia nitrogen exposure (Maas et al., 2012; Keppler, 2007; Wang et al., 2012; Widman et al., 2008). The underlying mechanism of ammonia toxicity in mollusc was not fully elucidated yet. In previous studies, we found that ammonia nitrogen exposure caused a series of adverse effects to the clam Ruditapes philippinarum, including decrease in lysosomal stability, disturbance of metabolic profiles, damage to the gill structure and variation of neurotransmitter concentrations (Cong et al., 2017). However, which genes and how many pathways were involved in the toxic reaction of $R$. philippinarum to ammonia nitrogen challenge? These questions were not answered clearly yet. In the present study, the expression profiles of related genes were detected by digital gene expression (DGE) analysis to preliminarily describe the genetic network of the $R$. Philippinarum clams to the ammonia exposure.

DGE is a kind of analysis approach widely used today to explore differentially expressed genes (DEGs) when the target organisms or their tissues are under a particular stress, with or without the background genome information. It has been quickly used in quite a few of aquatic organisms to detect their responses to external factors at gene level, such as Oryzias melastigma (Huang et al., 2012), Crassostrea gigas (Zhao et al., 2012) and Chlamys farreri (Hu et al., 2015). R. philippinarum is an important marine mollusc, distributed widely along the Chinese coastal area. As a sedentary habitant, $R$. philippinarum is more inclined to the environment pollutants including ammonia nitrogen. Among $R$. philippinarum's organs, gill is the first one to contact with the environment and probably is the first target of external pollutants. In the present study, $R$. philippinarum received ammonia exposures for 1 and 30 days respectively to find out the differentially expressed genes involved in acute and subacute toxicities of ammonia nitrogen. Gill tissues were used to analyze the gene expression profiles by using DGE technology, and validated by quantitative real-time PCR to identify the genes and pathways which were involved in the molecular reaction of clams against ammonia nitrogen exposure.

\section{Materials and methods}

\subsection{Animals and ammonia- $N$ exposure experiments}

Healthy clam $R$. philippinarum (averaging $3.56 \pm 0.35 \mathrm{~cm}$ in shell length) were collected from Yangma Island (with an average background $\mathrm{NH}_{3}-\mathrm{N}$ concentration of $0.0016 \mathrm{mg} / \mathrm{L}$ ), Yantai city. The clams were acclimated for 15 days in aerated and filtered seawater (19 $\left.\sim 20^{\circ} \mathrm{C}, \mathrm{pH} 8.0,32 \mathrm{psu}\right)$, and fed with a mixture of Isochrysis galbana and Chlorella vulgaris Beij. The seawater in each tank was changed twice every day just before and 2-h after the feeding. Stock solution ( $1 \mathrm{~mol} / \mathrm{L}$ ) of high purity $\mathrm{NH}_{4} \mathrm{Cl}$ was used as the source of the total ammonia. After the acclimation period, all of the clams were randomly divided into two groups as blank $(0 \mathrm{mg} / \mathrm{L})$ and ammonia nitrogen $(0.1 \mathrm{mg} / \mathrm{L})$ exposure groups with three replicate tanks respectively.

According to the annual reports on the environmental state of China, the actual concentration of ammonia nitrogen in the neritic China seas ranged from 0 to $19.32 \mathrm{mg} / \mathrm{L}$ with an average value of $1.82 \mathrm{mg} / \mathrm{L}$. Based on the result of lysosomal destabilization which was an indicator of cellular damage (Keppler, 2007; Aguirre-Martínez et al., 2013), our previous study suggested that 1-day exposure of $0.1 \mathrm{mg} / \mathrm{L}$ ammonia nitrogen could cause toxic effects to the calms, and induced significant changes in neurotransmitter concentrations, lysosomal stabilization and metabolite concentrations (Cong et al., 2017). And a 30day exposure of $0.1 \mathrm{mg} / \mathrm{L}$ ammonia nitrogen didn't cause massive mortality to the clams (data not shown). So $0.1 \mathrm{mg} / \mathrm{L}$ ammonia nitrogen was used in the present study to evaluate toxic reactions in clam $R$. philippinarum in an ammonia nitrogen polluted environment, and 1-day and 30-day durations of ammonia nitrogen were used to compare the effects of acute and subacute ammonia exposure in clams, respectively. During the 30-days' exposure experiment, gill tissues of the clams were collected into RNAlater Stabilization Solution (Thermo Fisher) at the 0, 1st and 30th-day, and used as Blank (B), A1, A30 group samples respectively. In order to diminish the individual difference among the same group, five individuals were pooled as one sample. And three samples were prepared in each group at each sampling time-point. The transcriptome samples in the blank, 1-day and 30-day exposure groups were designated as RpB, RpA1 and RpA30 respectively. In addition, another five individual clams from each group were collected as five samples to be used in the real-time RT-PCR experiment.

\subsection{Total RNA extraction and DGE sequencing}

RNA extraction from each sample was carried out following the manual instructions of the Trizol reagent. The purity, concentration and integrity of RNA samples were checked by using the NanoPhotometer ${ }^{\circ}$ spectrophotometer (IMPLEN, CA, USA), Qubit ${ }^{\circ}$ RNA Assay Kit in Qubit ${ }^{\circ}$ Library preparation for Transcriptome sequencing 2.0 Flurometer (Life Technologies, CA, USA) and RNA Nano 6000 Assay Kit of the Agilent Bioanalyzer 2100 system (Agilent Technologies, CA, USA), respectively. A total amount of $3 \mu \mathrm{g}$ RNA $\left(\mathrm{A}_{260} / \mathrm{A}_{280}=1.8\right)$ per sample was used as input material for further analysis. Sequencing libraries were generated using NEB Next ${ }^{\oplus}$ Ultra $^{\mathrm{TM}}$ RNA Library Prep Kit for Illumina ${ }^{\circledR}$ (NEB, USA) following manufacturer's recommendations, and library quality was assessed on the Agilent Bioanalyzer 2100 system. Then the clustered library was sequenced on an Illumina Hiseq 2500 platform and $125 \mathrm{bp} /$ $50 \mathrm{bp}$ paired/single-end reads were generated as raw data in fastq format.

\subsection{Bioinformatics analyses and in silico gene expression analyses}

Clean data were got by removing reads containing adapter, ploy-N and other low quality reads from raw data. Q20, Q30, GC-content and sequence duplication level of the clean data were all calculated. After that, transcriptome was assembled by pooling the clean data with high quality from all treatments together. Then gene functions were annotated based on several databases, including $\mathrm{Nr}$ (NCBI non-redundant protein sequences), Nt (NCBI non-redundant nucleotide sequences), Pfam (Protein family), KOG/COG (Clusters of Orthologous Groups of proteins), Swiss-Prot (A manually annotated and reviewed protein sequence database), KOG (KEGG Ortholog database) and GO (Gene Ontology). SNP calling was performed by GATK2 software with distance $>5$.

Gene expression levels were estimated by RSEM (Li and Dewey, 2011) for each sample. Clean data were mapped back onto the assembled transcriptome and readcount for each gene was obtained from the mapping results. Differential expression analyses of the blank and the ammonia-nitrogen exposed groups were performed by the DESeq $\mathrm{R}$ package (1.10.1). The resulting $P$ values were adjusted using the Benjamini and Hochberg's approach for controlling the false discovery rate. Genes with an adjusted $P$ value $<0.05$ found by DESeq were assigned as differentially expressed. In addition, a pheatmap was constructed according to the relative expression levels of the differentially expressed genes among the blank, 1-day and 30-day exposure groups (designated as RpB, RpA1 and RpA30, respectively).

\subsection{GO and KEGG analysis of the DGEs}

GO enrichment analysis of the DEGs was implemented by the GOseqR packages based on Wallenius non-central hyper-geometric distribution (Young et al., 2010), which can adjust for gene length bias in DEGs. KEGG (Kanehisa et al., 2008) pathway analysis was performed by KOBAS (Mao et al., 2005) software to enrich the differential expression genes. In addition, interaction between proteins from the DEG 
sequences in the transcriptome was predicted.

\subsection{Quantitative analysis by real-time RT-PCR}

To confirm that ammonia-nitrogen exposure induced genes differentially expressed in $R$. philippinarum, quantitative real-time PCR (qRTPCR) was performed using Prime Script RT reagent kit (TaKaRa, Dalian, China). Identification of ammonia nitrogen-response genes were carried out by BLASTX search against Nr, Nt, Pfam, Swiss-Prot, GO and KEGG database. Ten significantly expressed genes (with adjusted $P$ value $<$ 0.05 ) were selected as the targeted genes from membrane binding pathway, nervous and signal transduction pathway, transcriptional regulation pathway and glutamine metabolism pathway. Six reference candidate genes, including $18 S$ rDNA (18S), beta actin (Actin), beta tu-

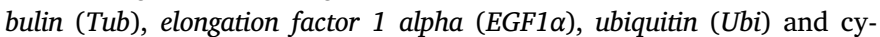
clophilin A(Cyclo), were screened for qPCR validation by geNorm and Normfinder softwares. The corresponding primers were designed by Primer Premier 5.0. Each primer was defined to a usual length of $20 \sim 25 \mathrm{bp}$, with the GC content between $40-60 \%$ and the $3^{\prime}$ of a primer ending in $\mathrm{C}$ or $\mathrm{G}$.

Total RNA was extracted from the gill tissues of clams in the blank and ammonia exposed groups, and $1 \mu \mathrm{g}$ of total RNA (A260/ A280 $=1.8$ ) in each sample was reversely transcripted to get the firststrand cDNA according to the protocols (PrimeScript ${ }^{\mathrm{TM}}$ RT-PCR Kit with gDNA Eraser, Takara). The qRT-PCR was carried out in an ABI 7500 Real-Time Detection System (Applied Biosystems) to find out the expression profiles of related genes. Gene-specific primers of six candidate genes and ten targets genes were shown in Table 1. The PCR amplifications were carried out in triplicate in a total volume of $20.0 \mu \mathrm{l}$, containing $10.0 \mu \mathrm{l}$ of $2 \times$ SYBR Green Master Mix (Applied Biosystems), $5.0 \mu \mathrm{l}$ of $1: 50$ diluted cDNA, $0.6 \mu \mathrm{l}$ of each primer $(10 \mu \mathrm{mol} / \mathrm{L})$, $3.8 \mu$ of PCR-grade DEPC-water. The PCR program was $50{ }^{\circ} \mathrm{C}$ for $2 \mathrm{~min}$ and $95{ }^{\circ} \mathrm{C}$ for $5 \mathrm{~min}$, followed by 40 cycles of $15 \mathrm{~s}$ at $94^{\circ} \mathrm{C}, 30 \mathrm{~s}$ at $60^{\circ} \mathrm{C}$.
At the end of each PCR amplication, dissociation curve analysis of final products was carried out to confirm that only one product was amplified and detected. Data were analyzed automatically with the ABI 7500 SDS software (Applied Biosystems). The comparative CT method was used to analyze the expression level of each gene (Livak and Schmittgen, 2001). The gene expression levels were given in terms of mean \pm S. D. $(n=5)$. The final data were subjected to one-way analysis of variance (one-way ANOVA) followed by least significant difference (LSD) analysis. Statistical significance was defined at $P<0.05$. In order to compare the variation trends of different genes detected by Illumina and qRT-PCR techniques, the final results were all expressed as $\log _{2}$ (fold change of An vs. B, $n=1$ or 30 ).

\section{Results}

\subsection{Analysis of sequenced data quality}

Because we haven't got the genome of $R$. philippinarum clam yet, a transcriptome was used as a reference to identify the differentially expressed genes induced by ammonia nitrogen. Therefore, a mixed RNA pool from the samples of the blank and $0.1 \mathrm{mg} / \mathrm{L}$ ammonia nitrogen exposed groups at 1 st and 30th day was sequenced as the reference transcriptome. The data qualities from each sample were shown in Table 2. After filtering low quality sequences by trimming sequencing adapters/poly-N and removing poor quality reads, there were $40,029,424$ clean reads $(97.17 \%$ of raw data) were obtained in the reference transcriptome. The longest transcript of each gene was regarded as its unigene, which was the reference to the following analysis. There were 219,534 transcripts with a mean length of 713 base pairs, and 151,283 unigenes with a mean length of 637 base pairs in the transcriptome.

Table 1

Primer sequences for housekeeper genes and targeted genes.

\begin{tabular}{|c|c|c|c|c|}
\hline Item & Gene Name & & Sequence $\left(5^{\prime}-3^{\prime}\right)$ & Length of amplicon (bp) \\
\hline \multirow[t]{12}{*}{ Housekeeper genes } & $18 S$ & Forward & ACTCAAGGGGAACCTC & 125 \\
\hline & & Reverse & TTAACCAGACAAATCGCTCCAC & \\
\hline & Actin & Forward & CTCCСTTGAGAAGAGCTACGA & 121 \\
\hline & & Reverse & GATACCAGCAGATTCCATACCC & \\
\hline & $T u b$ & Forward & AACACCGACGAGACATACTGC & 160 \\
\hline & & Reverse & CGTTCAACTGACCTGGGAAT & \\
\hline & EGF1 $\alpha$ & Forward & GAATGGTTGTTACCTTTGCTCC & 214 \\
\hline & & Reverse & ACGATGACCTGGGCATAGA & \\
\hline & Ubi & Forward & ACTCTTCATCTTGTGCTCCGTC & 240 \\
\hline & & Reverse & AAGATGGAGAGTGGACTCTTTCTG & \\
\hline & Cyclo & Forward & AACGGTACTGGAGGCAAGAG & 196 \\
\hline & & Reverse & TACCCTCAACTACTGAACCAAACA & \\
\hline \multirow[t]{20}{*}{ Targeted unigenes } & $T M D P$ & Forward & TGGTTGGTGGACTTGTTTCG & 155 \\
\hline & & Reverse & GACATCCGAGGATTCCGAGA & \\
\hline & $A B C A$ & Forward & GTACCGAGGCCAATAACCTAC & 200 \\
\hline & & Reverse & TGACAGAACTAAGCCGACCACT & \\
\hline & $T R P$ & Forward & GGCAATGTTCTAATGTAGCGTC & 108 \\
\hline & & Reverse & TTGCGTCTCTACTCAATGTGTTAC & \\
\hline & CYP450-like & Forward & AGAGGGCGAAGAGTCAGAAA & 161 \\
\hline & & Reverse & GTTTTGCCAACGAGTATAAGC & \\
\hline & Dat-like & Forward & ATCATTTCGGCGTTACAGAGA & 102 \\
\hline & & Reverse & CCATTGCAGCGTGAACTATC & \\
\hline & GS & Forward & GCTGAAGTTATGCCAGGACA & 151 \\
\hline & & Reverse & CTTCCATAGGTTTCGGGTCT & \\
\hline & FOX & Forward & TGCATGGCTATGAAAGAGACTAAGA & 200 \\
\hline & & Reverse & TCTACGTTTCTTGAACACACCATTT & \\
\hline & Apo X1 & Forward & GGAACAATGACACGCACGA & 108 \\
\hline & & Reverse & GTCACTGACCACCTCAAACCTA & \\
\hline & TG 1 & Forward & GCACATAATACAGCGTTCCAAC & 111 \\
\hline & & Reverse & ATAACAACATATCTTAGGTCACGC & \\
\hline & TG 2 & Forward & GCTGAAGTTATGCCAGGACA & 151 \\
\hline & & Reverse & CTTCCATAGGTTTCGGGTCT & \\
\hline
\end{tabular}


Table 2

Summary of the DGE data collected from the gills of $R$. philippinarum in response to ammonia-N.

\begin{tabular}{|c|c|c|c|c|c|c|c|c|c|}
\hline \multirow[t]{2}{*}{ Summery } & \multicolumn{3}{|l|}{ Blank group } & \multicolumn{3}{|c|}{ 1st - day group } & \multicolumn{3}{|c|}{ 30rd-day group } \\
\hline & RpB_1 & RpB_1 & RpB_1 & RpA1_1 & RpA1_1 & RpA1_1 & RpA30_1 & RpA30_1 & RpA30_1 \\
\hline Raw data & $11,293,884$ & $10,521,712$ & $12,837,253$ & $10,759,221$ & $11,550,358$ & $12,843,888$ & $12,166,006$ & $11,339,469$ & $13,062,181$ \\
\hline Clean data & $10,712,980$ & $10,461,708$ & $12,627,883$ & $10,441,740$ & $11,297,511$ & $12,810,505$ & $11,912,659$ & $11,117,448$ & $12,740,691$ \\
\hline Error rate (\%) & 0.01 & 0.01 & 0.01 & 0.01 & 0.01 & 0.01 & 0.01 & 0.01 & 0.01 \\
\hline Q20 & 98.64 & 98.64 & 98.64 & 98.63 & 98.65 & 98.52 & 98.65 & 98.63 & 98.65 \\
\hline Q30 & 97.34 & 97.33 & 97.35 & 97.33 & 97.37 & 97.11 & 97.29 & 97.24 & 97.29 \\
\hline GC content (\%) & 37.57 & 38.24 & 38.44 & 38.91 & 38.98 & 39 & 38.77 & 38.4 & 38.5 \\
\hline $\begin{array}{c}\text { Total mapped } \\
\text { (\%) }\end{array}$ & $\begin{array}{l}8,244,355 \\
(76.96 \%)\end{array}$ & $\begin{array}{l}8,114,696 \\
(77.57 \%)\end{array}$ & $\begin{array}{l}9,899,238 \\
(78.39 \%)\end{array}$ & $\begin{array}{l}8,216,239 \\
(78.69 \%)\end{array}$ & $\begin{array}{l}9,034,676 \\
(79.97 \%)\end{array}$ & $\begin{array}{l}9,970,928 \\
(77.83 \%)\end{array}$ & $\begin{array}{l}9,342,031 \\
(78.42 \%)\end{array}$ & $\begin{array}{l}8,645,563 \\
(77.77 \%)\end{array}$ & $\begin{array}{l}9,939,857 \\
(78.02 \%)\end{array}$ \\
\hline
\end{tabular}

\subsection{Functional annotation and classification of the transcriptome}

Putative functions of proteins encoded by the 151,283 genes were predicted by Nr, Nt, Pfam, KOG/COG, Swiss-Prot, KO and GO database. The results showed that there were $38,479(25.43 \%), 2884(1.9 \%)$, 13,078 (8.64\%), 26,252 (17.35\%), 35847 (23.69\%), 36,654 (24.22\%), 18,434 (12.18\%), $1772(1.17 \%), 49,888(32.97 \%)$ genes homologous to the sequences in the Nr, Nt, Pfam, KOG/COG, Swiss-Prot, KO and GO databases, respectively (Table 3). There were 1772 unigenes $(1.17 \%)$ were annotated in all databases and 49,888 unigenes (32.97\%) were annotated in at least one database. In total, all of the 151,283 unigenes $(100 \%)$ were functionally annotated.

By Blast X search, we found out that the genes in $R$. philippinarum transcriptome showed homologies to the sequences from other organisms. Among them, $30.1 \%, 13.2 \%, 6.4 \%$ and $6.2 \%$ of the genes exhibited significant homologies to the sequences in Crassostrea gigas, Lottia gigantean, Aplysia californica and Opisthorchis viverrini, respectively (Fig. 1a). The $E$-value distribution analysis revealed that $40.2 \%$ sequences were highly conserved with an $E$-value $<10^{-45}$, and $52.8 \%$ sequences showed strong homology with an $E$-value $<10^{-30}$ (Fig. 1b). According to the similarity distribution, $19.6 \%$ of the sequences had strong match ( $>80 \%$ ) with the deposited sequences, $45.2 \%$ sequences showed $60-80 \%$ match, and $34.7 \%$ had $40-60 \%$ match (Fig. 1c).

Based on the annotation results of $\mathrm{Nr}$ and Pfam, 36,654 (24.22\%) of the mapped genes could be assigned to GO categories of biological process, cellular component, molecular function (Fig. 2). The category of biological process was made up to 21 subcategories, of which the major one was macromolecule metabolic process with 11,630 (31.73\%) genes. The category of cellular component contained 15 subcategories, among which cellular components was the biggest one with 9628 (26.26\%) genes. The category of molecular function was consisted of 12 subcategories, of which the major one was cation binding with 5760 (15.71\%) genes (Fig. 2a). And 18,434 (12.18\%) of the mapped genes were assigned into 26 groups in KOG database (Fig. 2b), of which the (T) signal transduction mechanism was the largest group with 3942 (21.38\%) genes, followed by (R) endocrine system with 1019 (5.5\%) genes, translation with 970 (5.3\%) genes, and transport and catabolism with $921(5.0 \%)$ genes. A total of 13,078 genes were characterized into 5 special KEGG pathways (Fig. 2c), including cellular process $(13.28 \%$,

Table 3

Functional annotation of the $R$. philippinarum transcriptome.

\begin{tabular}{lll}
\hline Annotated Database & Number of Unigenes & Percentage (\%) \\
\hline NR & 38479 & 25.43 \\
NT & 2884 & 1.9 \\
KO & 13078 & 8.64 \\
SwissProt & 26252 & 17.35 \\
PFAM & 35847 & 23.69 \\
GO & 36654 & 24.22 \\
KOG & 18434 & 12.18 \\
Total Unigenes & 151283 & 100 \\
\hline
\end{tabular}

A), environmental information processing (19.64\%, B), genetic information processing $(12.58 \%, \mathrm{C})$, metabolism $(23.06 \%$, D), organismal systems (31.44\%). The transcriptome and the following DGE data have been deposited at Genbank under the accession number SRP116794.

\subsection{Digital gene expression (DGE) analysis}

DGE analysis was conducted to identify the related genes in response to ammonia nitrogen exposure. All of the tagged sequences in each sample were mapped to the assembled transcriptome library of $R$. philippinarum using RSEM software (Li and Dewey, 2011). To mitigate the effect of transcript length on the calculation of gene differential expression, FPKM method (expected number of Fragments Per Kilo base of transcript sequence per Millions base pairs sequenced) was introduced in the calculation. If the FPKM values are over 0.3 , the genes are regarded expressed. The number of raw reads produced for blank and experiment groups ranged from 10.5 to 13.0 million (Table 2). Among the clean data in each group, the percentages of sequences mapped to genes ranged from $76.96 \%$ to $79.97 \%$, and the error rates of base sequencing were all $0.1 \%$. In conclusion, all the data were suitable for further gene expression analysis.

Compared with the blank group, DGE analysis revealed that there were 65 genes significantly up-regulated and 35 genes significantly down-regulated in the A1 group. There were 106 unigenes up-regulated and 143 genes down-regulated in the A30 group. However, long duration of ammonia nitrogen exposure caused 161 genes differentially regulated in the A30 group compared with the A1 group, of which 94 genes were up-regulated and 67 genes were down-regulated (Fig. 3). The hierarchical clustering pheatmap displayed globally and intuitively on the DEGs expression patterns (Fig. 4). It can be seen that the expression patterns of both the A1 and the A30 groups were distinguishable from the blank group.

\subsection{GO enrichment and KEGG pathways analysis of DEGs}

The DEGs were assigned to the GO database by GO seq to characterize the involved biological processes upon ammonia nitrogen exposure. No significant enriched GO terms were found in A1 or A30 groups compared with the blank group. The first five GO terms in A1 group included substance binding (GO: 0005488, 20genes), cellular process (GO: 0009987, 18genes), single-organism process (GO: 0044699, 14 genes), membrane (GO: 0016020, 14 genes), metabolic process (GO: 0008152, 14 genes). However, the GO terms of the DEGs in A30 group dispersed in a wider range, of which the first five were cellular process (GO: 0009987, 70 genes), substance binding (GO: 0005488, 59 genes), catalytic activity (GO: 0003824, 58 genes), metabolic process (GO: 0008152, 56 genes), single-organism process (GO: 0044699, 53 genes).

Although no significant enriched GO terms were found after ammonia nitrogen exposure, the genes with significantly changed profiles (adj $P<0.05$ ) were analyzed according to their GO terms to describe 
a Species classification

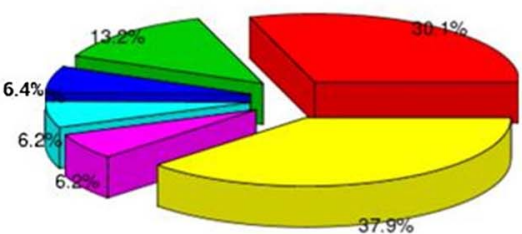
E Crassostrea gigas
E Lottia gigantea - Aplysia californica

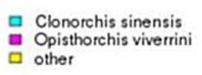

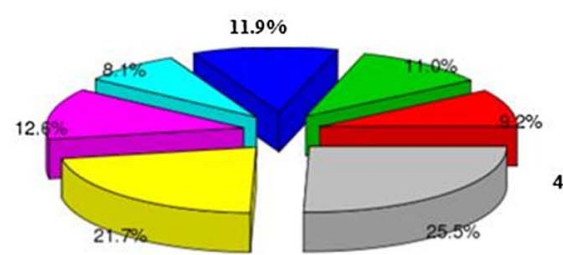

$\begin{aligned}= & 0 \\ = & 0-1 e-100 \\ = & 0 \cdot 100 \sim 1 e \cdot 60\end{aligned}$ - $10 \cdot 100 \sim 1 e \cdot 60$

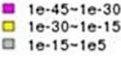

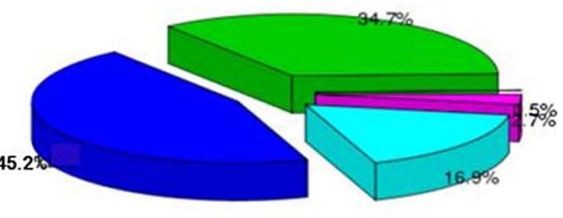

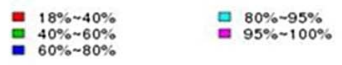

Fig. 1. Functional classification of the transcriptome. (a) Species classification. (b) E-value distribution. (c) Similarity distribution.

the toxicological network of ammonia nitrogen on $R$. philippinarum, which were shown in Table 4 (1-day duration) and Table 5 (30-day duration) respectively. According to Table 4, 1-day duration of ammonia-nitrogen exposure could significantly down-regulate the genes related to stimulus response, binding and transmembrane transportation of metal ion, and up-regulated the genes involved in stress-response, ion-binding, signal transduction, receptors, protein processing, cell adhesion, conjugation and membrane formation. A 30-day duration of ammonia nitrogen exposure caused significant down-regulation of the genes related to stimulus response, immune response, protein processing (synthesis, modification, folding and transporting), substance transporting, cellular component organization, chaperone and oxidoreductase activities, as well as binding. In addition, the 30-day duration of ammonia nitrogen significantly up-regulated six kinds of genes which were involved in response to stress/stimulus, signal transduction, important cellular compounds metabolism, catalytic reaction, intracellular and transmembrane transporting, and ion/receptor/organic substance binding.

The DEGs were also assigned to KEGG database to find out the correlated pathways of biochemical metabolite and signal transduction, with corrected $P$ value of 0.05 as the cutoff. One-day ammonia nitrogen exposure caused the DEGs enriched in 13 pathways, of which the first 4 included Dorso-ventral axis formation (ko04320), Notch signaling pathway (ko04330), thyroid hormone signaling pathway (ko04919) and protein processing in endoplasmic reticulum (ko05206). KEGG analysis also found that 30-day exposure caused the DGEs significantly enriched in gap junction (ko04540), pathogenic Escherichia coli infection (ko05130), bile secretion (4ko04976), GABAergic synapse (ko04727), alanine, aspartate and glutamate metabolism (ko00250), phagosome (ko04145), ABC transporters (ko02010). Between A1 and

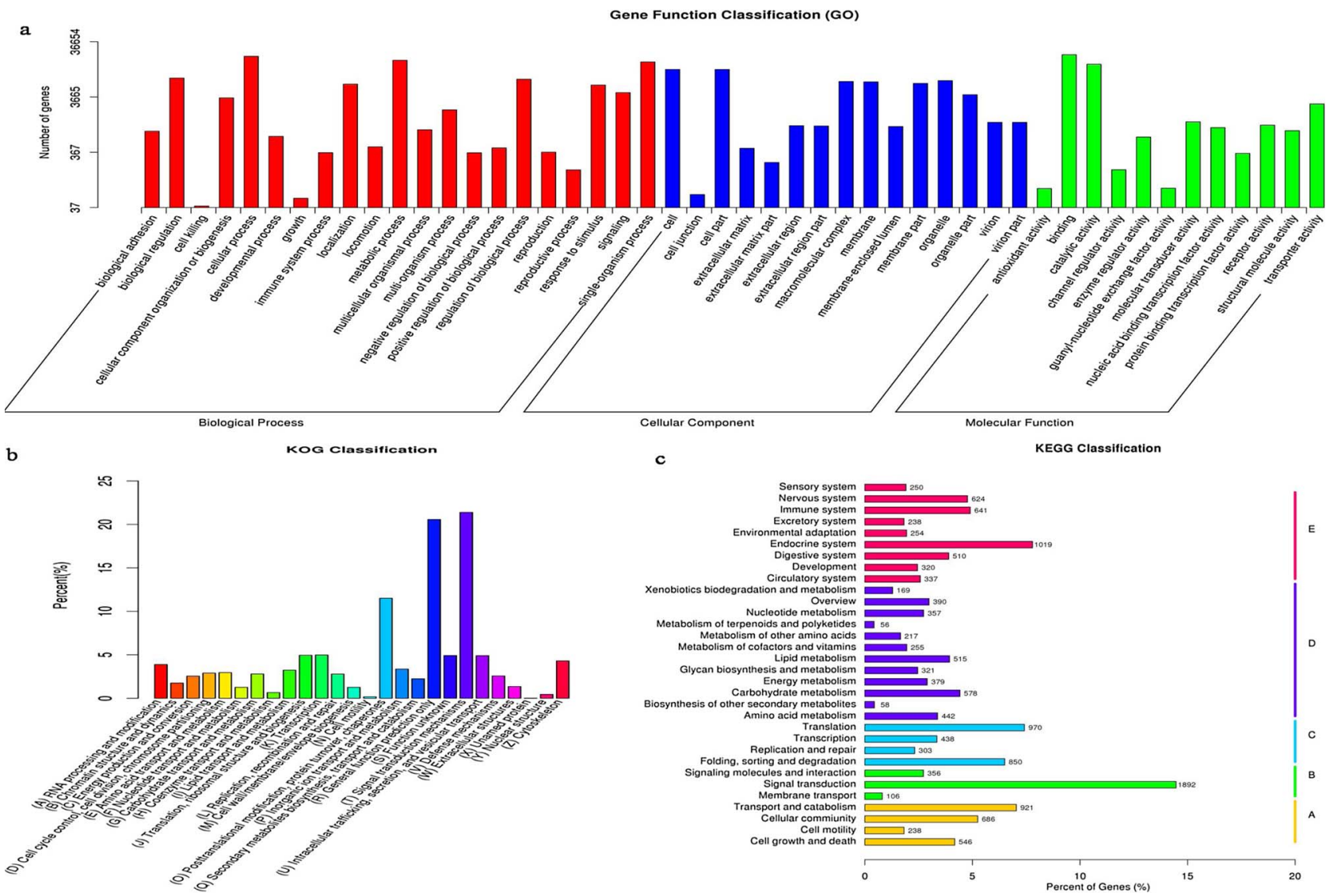

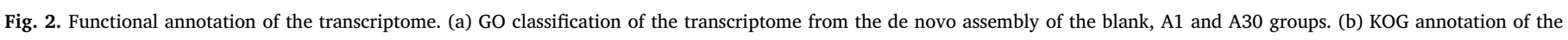
putative proteins. (c) KEGG classification of the transcriptome. 

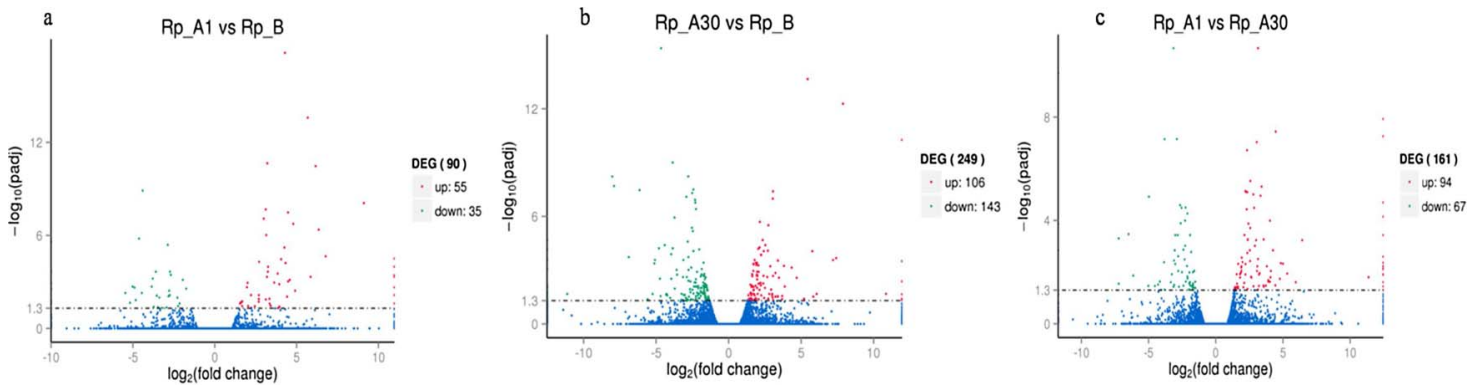

Fig. 3. DEG Volcanoplots among different treatments.

A30 groups, there was no significant difference in their enriched pathways.

From the enriched KEGG pathways of different exposure durations, it can be seen that one-day exposure to ammonia nitrogen significantly affected the expression profiles of genes involved in neuron formation (Dorso-ventral axis formation, up-regulated), signal transduction in cell proliferation and apoptosis (Notch signaling, up-regulated), hormone signaling (thyroid hormone signaling, up-regulated) and protein processing (protein processing in endoplasmic reticulum, down-regulated) pathways. However, 30-day exposure led to significant regulation of genes in junction (gap junction, up-regulated), immunity (pathogenic Escherichia coli infection and phagosome, up-regulated), signal and hormone transduction (ABC transporters and GABAergic synapse, both up-regulated), as well as key material metabolism (bile, alanine, aspartate and glutamate, up-regulated).

\subsection{QRT-PCR validation of differentially expressed genes}

In order to confirm the results of transcriptome, ten of the differentially expressed genes were selected from DGE libraries to detect their expression levels by qRT-PCR (Fig. 5). These genes included TM2 domain-containing protein (TMDP), ATP-binding cassette sub-family A member $(A B C A)$, transcriptional regulatory protein (TRP), cytochrome P450-like (CYP450-like), dopamine N-acetyltransferase-like (Dat-like), glutamine synthetase (GS), forkhead box protein (FOX), apolipoproteinlike isoform X1 (Apo X1), transglutaminase (TG1, TG2). RNA samples from another five biological replicate sets were used as the templates for qRT-PCR. Each unigene was found to be a single product by the melting-curve analysis. According to qRT-PCR results of the target genes validated by the reference gene VpEGF1 $\alpha$ (GenBank NO JK845897), long-term exposure of ammonia nitrogen caused 4 unigenes

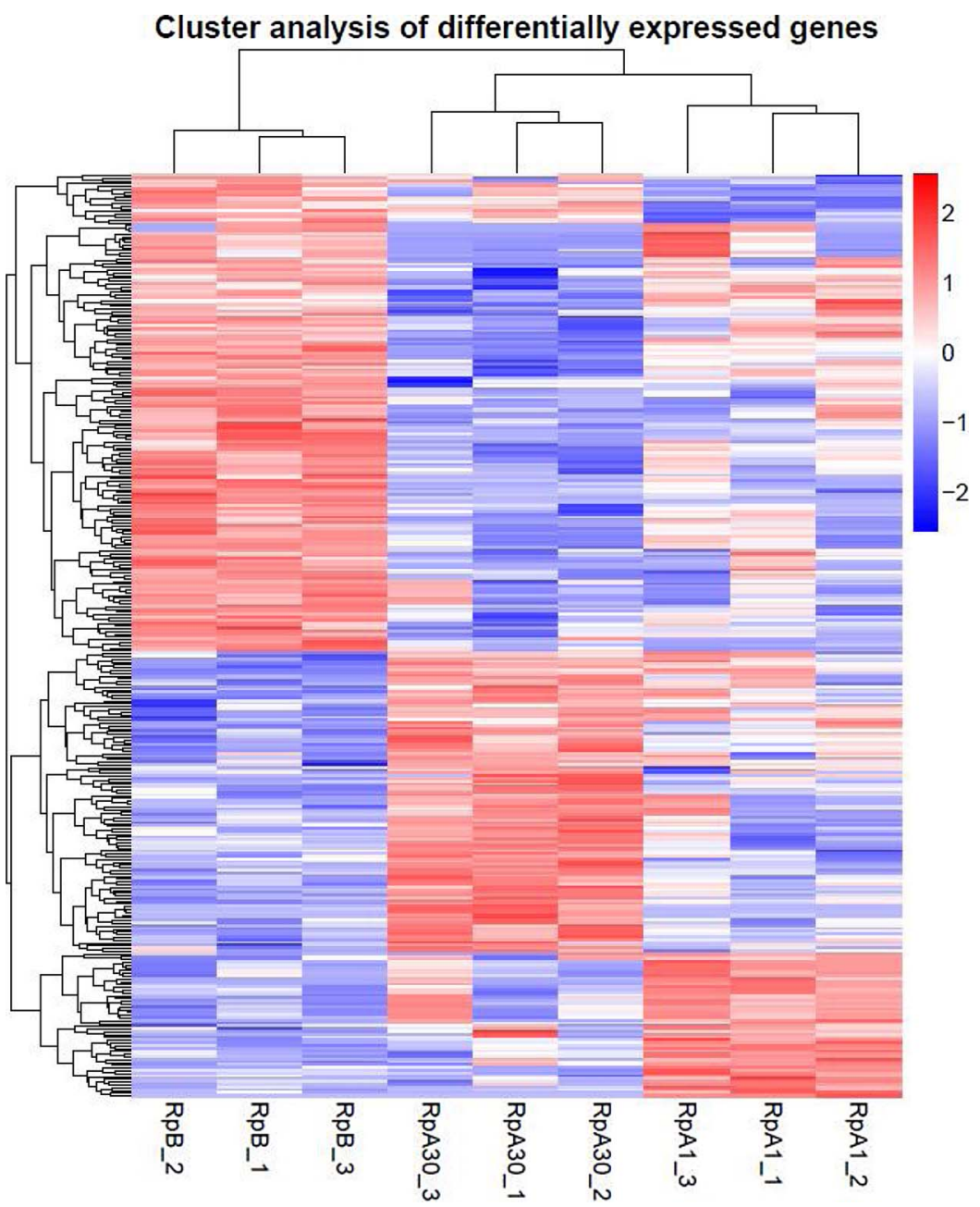

Fig. 4. In silico gene transcription analysis of different exposed groups, each with three replicates (RpB, the blank groups; $\mathrm{RpA} 1$, the $\mathrm{NH}_{3}-\mathrm{N}$ exposed groups for one day; $\mathrm{RpA} 30$, the $\mathrm{NH}_{3}-\mathrm{N}$ exposed groups for thirty days). Red color suggests high expression and blue color represents down expression. (For interpretation of the references to colour in this figure legend, the reader is referred to the web version of this article.) 
Table 4

List of genes with significant changed $\mathrm{GO}$ terms after $\mathrm{NH}_{3}-\mathrm{N}$ exposure for 1 day.

\begin{tabular}{|c|c|c|c|c|}
\hline \multirow[t]{2}{*}{ Description } & \multicolumn{2}{|c|}{ Readcounts } & \multirow[t]{2}{*}{ FC } & \multirow[t]{2}{*}{ Function } \\
\hline & $\mathrm{A} 1$ & B & & \\
\hline \multicolumn{5}{|c|}{ Significantly down-regulated genes } \\
\hline PIF1-like helicase & 0 & 78.46 & -inf & response to stimulus (telomere maintenance) \\
\hline DSBA-like thioredoxin & 0 & 34.97 & -inf & response to stimulus (oxidoreductase activity) \\
\hline Growth-arrest specific micro-tubule & 12.61 & 152.75 & -3.60 & response to stimulus (regulation of cell death) \\
\hline STAT protein & 0 & 24.83 & -inf & DNA binding \\
\hline nucleotide exchange factor SIL1 & 212.95 & 823.43 & -1.95 & binding \\
\hline Fibronectin type III domain & 0 & 26.02 & -inf & binding \\
\hline GRP78 & 188.96 & 1750.39 & -3.21 & binding \\
\hline ZIP Zinc transporter & 43.96 & 282.23 & -2.69 & zinc transmembrane transport \\
\hline Ferrous iron transport protein $\mathrm{B}$ & 228.21 & 1522.46 & -2.74 & ferrous iron transmembrane transporter activity \\
\hline \multicolumn{5}{|c|}{ Significantly up-regulated genes } \\
\hline DNA double-strand break repair and V(D)J recombination protein XRCC4 & 888.74 & 95.73 & 3.21 & response to stress \\
\hline Coleoptericin & 32.89 & 0 & Inf & response to stimulus \\
\hline DNA repair protein Ercc1 & 108.74 & 0 & Inf & response to DNA damage stimulus \\
\hline Cytochrome P450 & 842.88 & 88.67 & 3.25 & oxidoreductase activity \\
\hline EGF-like domain-containing protein (EGFL) & 205.75 & 4 & 5.69 & calcium ion binding \\
\hline Sushi-repeat-containing protein (SRP) & 288.18 & 9.54 & 4.92 & calcium ion binding \\
\hline Sushi, von Willebrand factor type A, EGF and pentraxin domain-containing protein (SVEP) & 148.66 & 6.66 & 4.48 & calcium ion binding \\
\hline Sushi repeat-containing protein 2 (SRPX2) & 235.14 & 8.45 & 4.80 & calcium ion binding \\
\hline Calcium-binding EGF (cbEGF) & 296.61 & 72.21 & 2.04 & calcium ion binding \\
\hline fibulin $1 / 2$ & 677.24 & 47.05 & 3.85 & ion binding \\
\hline Neurogenic locus notch like protein 2 (NOTCH2) & 66.56 & 3.11 & 4.42 & calcium activated cation channel activity \\
\hline Rabaptin & 191.60 & 21.97 & 3.12 & Neuro-signal transduction \\
\hline Transcriptional regulatory protein & 291.66 & 36.59 & 3.00 & signal transduction \\
\hline Nine Cysteines Domain of family 3 GPCR & 60.73 & 3.02 & 4.33 & receptor activity \\
\hline ATP-binding cassette sub-family A member & 846.08 & 271.10 & 1.64 & ion transmembrane transport \\
\hline Multidrug resistance protein 1 & 440.93 & 109.69 & 2.01 & transporter activity \\
\hline Oligosaccharyltransferase subunit Ribophorin II & 61.21 & 0 & Inf & macromolecule modification \\
\hline Sequestosome-1 & 5378.96 & 1817.93 & 1.57 & ubiquitin-dependent protein catabolic process \\
\hline Acyltransferase & 584.91 & 181.87 & 1.69 & transferase activity \\
\hline Lysosomal aspartic protease & 3557.96 & 1214.47 & 1.55 & hydrolase activity \\
\hline SAM dependent carboxyl methyltransferase & 88.37 & 3.69 & 4.58 & exocytosis \\
\hline basement membrane-specific heparan sulfate proteoglycancore protein-like 1 & 370.17 & 36.49 & 3.34 & cell adhesion \\
\hline Neural cell adhesion molecule 2 & 303.80 & 35.00 & 3.12 & Neural cell adhesion \\
\hline basement membrane-specific heparan sulfate proteoglycan core protein-like 2 & 73.99 & 6.94 & 3.41 & cell adhesion \\
\hline Claudin tight junction & 451.40 & 115.51 & 1.97 & membrane \\
\hline
\end{tabular}

(TMDP, ABCA, CYP450-like, TG2) significantly down-regulated compared with those after acute exposure. However, another 5 unigenes (Dat-like, GS, FOX, Apo X1 and TG1) were found significantly upregulated after 30-day exposure compared with those after 1-day exposure. Of the ten tested genes, only the regulation trend of TRP gene detected by qRT-PCR was not consistent with that detected by Illumina. It indicated that most of the expression profiles of unigenes detected by Illumina RNA-seq technology were consistent with those qualified by qRT-PCR, and the transcriptome results were reliable for further analysis of ammonia-responsive genes.

\section{Discussion}

Our previous study revealed that ammonia exposure could significantly reduce the integrity of lysosome membrane, decrease the contents of glutamate and branched chain amino acid, decrease ATP supply, increase apoptosis ratios, decrease contents of neurotransmitters, reduce basal layer inside the filaments with the emergence of xenobiotic substances (Cong et al., 2017). It suggested that ammonia nitrogen exposure brought detrimental toxicity to $R$. philippinarum. Given that gill tissue is important for the clam in feeding and respiration functions, the aberrant gill structures caused by ammonia exposure is supposed to be detrimental for the survival of $R$. philippinarum. However, little information was obtained to explain the molecular mechanism of ammonia nitrogen on the clams. In order to well elucidate the genetic mechanisms underlying severe damage of ammonia nitrogen exposure on the gill tissues of $R$. philippinarum, DGE analysis technique was applied and yielded a number of expressed sequences in the present study. After assemblage, these sequences were annotated and developed into a database for $R$. philippinarum gill tissue. The annotated functional sequences would be searched and further investigated. It is of particular importance for well understanding toxic mechanism of ammonia on a mollusc without complete genome background and also for pollution management in mollusc aquaculture.

Differentially expressed genes after ammonia nitrogen exposure were established into a DEG library, with considerate homologies to the known sequences of other molluscs, such as $C$. gigas and $L$. gigantean. It is convenient to discriminate the involved pathways of $R$. philippinarum after encountering ammonia nitrogen. In order to describe the toxicological overview of ammonia nitrogen on $R$. philippinarum, the differentially changed DEGs after 1- or 30-day exposures were performed with GO enrichment and KEGG pathway analysis. And the main functions of DEGs would lay a good foundation to understand the potential mechanism of ammonia toxicity.

After systematical GO analysis, some toxic effects of ammonia nitrogen exposure could be predicted according to the genes with differential expression patterns. First of all, it can be seen that the immune system of $R$. philippinarum would be heavily weakened according to the variation profiles of immune-related genes. These genes included coleoptericin, interferon-induced protein 44-like (IFI44L), alpha-2 macroglobulin (A2M), C-type lectin 9a, complement component C3, tumor necrosis factor-like protein and ligand superfamily member 10 , coleoptericin, sialic acid binding lectin and so on. In Table 4, coleoptericin gene was significantly up-regulated after short-term exposure of ammonia nitrogen. Since coleoptericin is a kind of antibacterial peptide in invertebrate immune system (Zhu et al., 2014). The significant up- 
Table 5

List of the genes with significant changed GO terms after $\mathrm{NH}_{3}-\mathrm{N}$ exposure for 30 day.

\begin{tabular}{|c|c|c|c|c|}
\hline \multirow[t]{2}{*}{ Description } & \multicolumn{2}{|c|}{ Readcounts } & \multirow[t]{2}{*}{ FC } & \multirow[t]{2}{*}{ Function } \\
\hline & A30 & B & & \\
\hline \multicolumn{5}{|l|}{ Significantly down-regulated genes } \\
\hline suppressor of cytokine signalling-2 & 582.19 & 2208.44 & -1.92 & response to stimulus \\
\hline C-type lectin 9a & 75.10 & 321.12 & -2.1 & response to stimulus \\
\hline inhibitor of apoptosis protein 1 and 2 & 86.66 & 267.77 & -1.63 & response to stimulus \\
\hline tumor necrosis factor-like protein & 488.39 & 1399.82 & -1.52 & Immune response \\
\hline Tumor necrosis factor ligand superfamily member 10 & 462.81 & 1177.93 & -1.35 & Immune response \\
\hline interferon-induced protein 44-like (ILL44) & 934.18 & 4226.34 & -2.18 & Immune response against virus \\
\hline Alpha-2-macroglobulin & 37.36 & 136.15 & -1.87 & Immune response \\
\hline complement component $\mathrm{C} 3$ & 68.17 & 221.09 & -1.7 & retrograde vesicle-mediated transport, Golgi to ER \\
\hline FKBP-type peptidyl-prolyl cis-trans isomerase & 74.64 & 229.78 & -1.62 & protein folding \\
\hline Protein arginine N-methyltransferase 1 & 433.12 & 1221.55 & -1.5 & protein methyltransferase activity \\
\hline Tryptophanyl-tRNA synthetase & 191.26 & 599.96 & -1.65 & catalytic activity \\
\hline Pterin 4 alpha carbinolamine dehydratase & 531.59 & 1494.99 & -1.49 & dehydratase activity \\
\hline asparaginyl-tRNA synthetase & 20.03 & 87.09 & -2.12 & tRNA metabolic process \\
\hline E3 ubiquitin-protein ligase & 90.87 & 261.97 & -1.53 & cation transport \\
\hline $\mathrm{Na}^{+}$dependent nucleoside transporter & 68.67 & 209.81 & -1.61 & organic substance transport \\
\hline sushi, von Willebrand factor type A, EGF and pentraxin domain-containing protein 1-like & 462.15 & 2491.41 & -2.43 & carbohydrate transmembrane transporter activity \\
\hline Phospholipase A2 isozymes PA3A/PA3B/PA5 & 272.71 & 725.12 & -1.41 & cellular lipid metabolic process \\
\hline Malonyl-CoA decarboxylase & 298.61 & 980.50 & -1.72 & cellular lipid metabolic process \\
\hline Pescadillo-like protein & 98.17 & 295.69 & -1.59 & cellular component biogenesis \\
\hline Cartilage intermediate layer protein 1 & 114.66 & 793.31 & -2.79 & cellular macromolecule catabolic process \\
\hline Mucolipin-3 & 1.19 & 23.73 & -4.31 & cellular component organization or biogenesis \\
\hline Ankyrin repeat domain-containing protein & 84.16 & 319.08 & -1.928 & cell adhesion \\
\hline Hypoxia up-regulated protein 1 & 699.93 & 2161.30 & -1.63 & Molecular chaperones GRP170/SIL1 \\
\hline heat shock 70kDa protein 5 & 3142.59 & 10394.61 & -1.73 & HSP70 superfamily \\
\hline cysteine dioxygenase & 2574.68 & 13466.01 & -2.39 & oxidoreductase activity \\
\hline tyrosinase-like protein tyr-1 & 42.74 & 192.05 & -2.19 & oxidoreductase activity \\
\hline Fibropellin-3 & 92.16 & 254.34 & -1.46 & chitin binding \\
\hline Sushi domain-containing protein 1 & 6.17 & 81.77 & -3.73 & $\mathrm{Ca}^{2+}$-binding \\
\hline \multicolumn{5}{|l|}{ Significantly up-regulated genes } \\
\hline Coleoptericin & 19.02 & 0 & Inf & response to stress \\
\hline Cytochrome P450 & 64.84 & 8.10 & 3 & cellular response to stimulus \\
\hline Acetyltransferase (GNAT) family & 282.61 & 99.27 & 1.51 & response to stress \\
\hline catalase & 3421.72 & 1324.85 & 1.37 & response to stimulus \\
\hline selenium binding protein & 2818.95 & 631.42 & 2.16 & response to stimulus \\
\hline СYP356A1 & 81.29 & 9.66 & 3.07 & response to stimulus \\
\hline Perlucin & 263.67 & 78.89 & 1.74 & response to stimulus \\
\hline sialic acid binding lectin & 367.14 & 72.12 & 2.35 & response to stimulus \\
\hline Kappa-type opioid receptor & 194.26 & 23.43 & 3.05 & signal transduction \\
\hline neurotransmitter transporter & 184.13 & 34.37 & 2.42 & neurotransmitter transporter activity \\
\hline dopamine $\mathrm{N}$-acetyltransferase-like & 323.20 & 38.63 & 3.06 & $\mathrm{~N}$-acetyltransferase activity \\
\hline transglutaminase 1 & 478.45 & 166.29 & 1.52 & cellular protein modification process \\
\hline Pyridine nucleotide-disulphide oxidoreductase & 211.26 & 44.63 & 2.24 & cellular aromatic compound metabolic process \\
\hline GPI ethanolamine phosphate transferase & 134.91 & 32.25 & 2.06 & macromolecule biosynthetic process \\
\hline Dolichyl-phosphate-mannose-protein mannosyltransferase & 122.42 & 0 & Inf & glycoprotein biosynthetic process \\
\hline Interferon-induced very large GTPase & 405.16 & 92.41 & 2.13 & fatty acid metabolic process \\
\hline P-glycoprotein & 3084.00 & 883.44 & 1.8 & organonitrogen compound metabolic process \\
\hline Sulfotransferase family cytosolic $1 \mathrm{~B}$ member 1 & 162.34 & 11.51 & 3.82 & catalytic activity \\
\hline multidrug resistance protein $1 \mathrm{~A}$-like & 1260.02 & 404.39 & 1.64 & catalytic activity \\
\hline phenylalanine-4-hydroxylase & 625.28 & 221.48 & 1.5 & catalytic activity \\
\hline arginine kinase & 674.75 & 171.80 & 1.97 & catalytic activity \\
\hline glutaminase & 106.46 & 28.60 & 1.9 & catalytic activity \\
\hline aryl sulfotransferase & 29.58 & 2.82 & 3.39 & catalytic activity \\
\hline Glutamine synthetase & 132.65 & 33.97 & 1.96 & catalytic activity \\
\hline Interferon-inducible GTPase & 200.50 & 3.65 & 5.78 & catalytic activity \\
\hline para-nitrobenzyl esterase & 250.37 & 60.15 & 2.06 & catalytic activity \\
\hline sigma class glutathione S-transferase & 1968.26 & 551.57 & 1.84 & catalytic activity \\
\hline Prolyl oligopeptidase & 439.70 & 116.93 & 1.91 & catalytic activity \\
\hline Proprotein convertase subtilisin/kexin type $5 / 6$ & 1364.22 & 437.26 & 1.64 & proteolysis \\
\hline Ileal sodium/bile acid cotransporter & 307.64 & 77.15 & 1.99 & bile acid and bile salt transport \\
\hline Sodium/calcium exchanger protein & 177.00 & 26.39 & 2.74 & transmembrane transport \\
\hline Growth-arrest specific micro-tubule binding & 48.31 & 5.13 & 3.23 & transmembrane transport \\
\hline Sodium/glucose cotransporter & 242.09 & 82.44 & 1.55 & transmembrane transport \\
\hline heat shock protein 22 isoform 2 & 8117.61 & 2458.01 & 1.72 & passive transmembrane transporter activity \\
\hline Sodium/glucose cotransporter 4 & 92.83 & 23.09 & 2.01 & transmembrane transport \\
\hline Excitatory amino acid transporter 1 & 7807.72 & 2371.61 & 1.72 & ion transmembrane transporter activity \\
\hline Phosphatidylinositol-glycan biosynthesis class S protein & 14.02 & 0 & Inf & intracellular protein transport \\
\hline forkhead box protein $\mathrm{J} 1$ & 267.90 & 94.13 & 1.51 & binding \\
\hline beta tubulin & 4622.11 & 1118.41 & 2.05 & binding \\
\hline Fibronectin type III & 118.88 & 11.23 & 3.4 & metal ion binding \\
\hline Transient receptor potential cation channel & 67.87 & 11.94 & 2.51 & cation binding \\
\hline
\end{tabular}




\begin{tabular}{|c|c|c|c|c|}
\hline \multirow[t]{2}{*}{ Description } & \multicolumn{2}{|c|}{ Readcounts } & \multirow[t]{2}{*}{ FC } & \multirow[t]{2}{*}{ Function } \\
\hline & A30 & B & & \\
\hline 4-aminobutyrate aminotransferase & 4256.42 & 1107.99 & 1.94 & metal ion binding \\
\hline sarcoplasmic calcium-binding protein & 472.41 & 111.98 & 2.07 & transition metal ion binding \\
\hline Down syndrome cell adhesion molecule & 235.50 & 60.59 & 1.96 & receptor binding \\
\hline Metabotropic glutamate receptor 7 & 2215.52 & 885.49 & 1.32 & carbohydrate binding \\
\hline
\end{tabular}

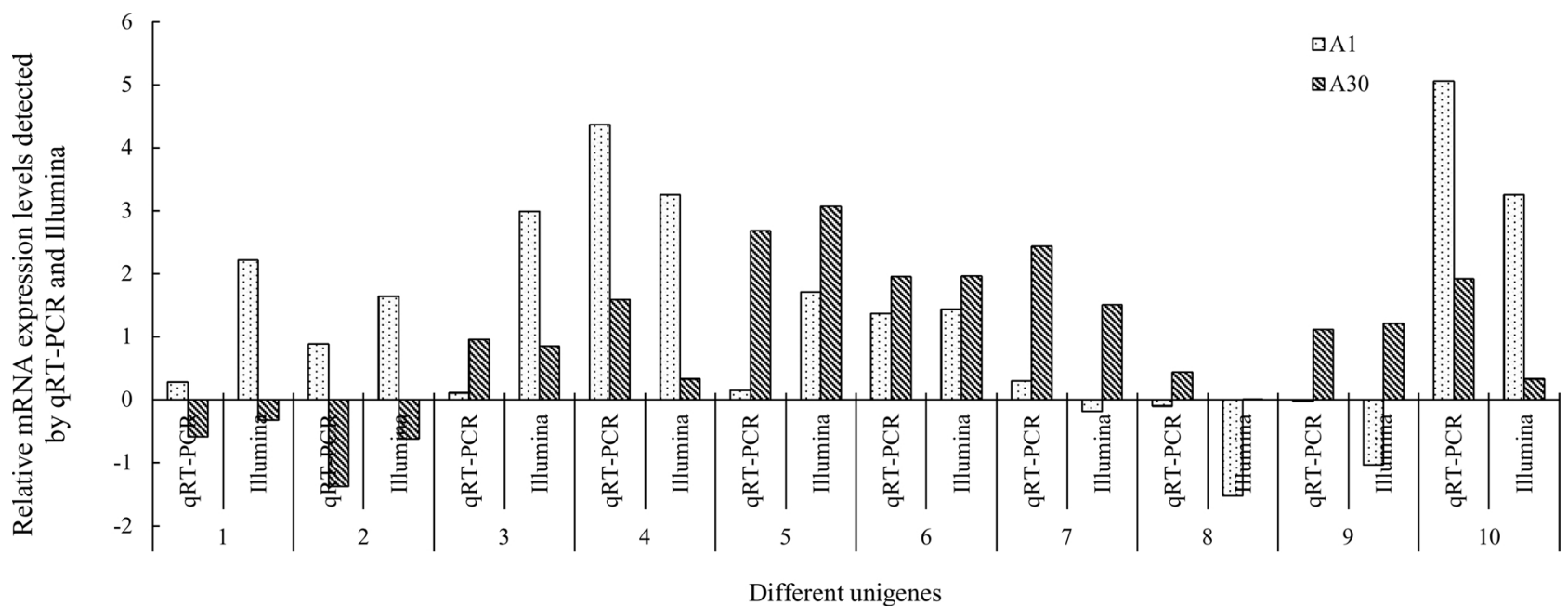

Fig. 5. Validation RNA-seq profiles by qRT-PCR for the samples after 1 and 30 days' exposure of ammonia nitrogen.

Note: 1. TMDP; 2. ABCA; 3. TRP; 4. CYP450-like; 5. Dat-like; 6. GS; 7. FOX; 8. Apo X1; 9. TG1; 10. TG2.

regulation of coleoptericin gene suggested that a short-term exposure of ammonia nitrogen would increase the opportunities of bacterial infection to $R$. philippinarum. In addition, immune-related genes were significantly changed after a 30-day exposure of ammonia nitrogen (Table 5). Among them, IFI44L is a kind of critical protein in host immune response to viral infections and can be used as molecular signature for viral infection diagnosis (Ngo et al., 2015). C-type lectin 9a belongs to the NK cell receptor group of C-type lectins and plays important roles in apoptosis and immune response against pathogens (Sancho et al., 2008). Complement component C3 is a stable circulating complement component that can facilitate both phagocytosis and bacterial killing but decreased after trauma (Shatney and Benner, 1985). Tumor necrosis factor-like protein and tumor necrosis factor ligand superfamily member 10 were both important immune factors (Ślebioda and Kmieć, 2014; Šedý et al., 2015). Alpha-2 macroglobulin (A2 M) is a major component of the innate immune system, as a modulator of prophenoloxidase system against bacterial infection (Ponprateep et al., 2017). Therefore, the significant down-regulations of the immune-related genes suggested that the immune abilities of $R$. philippinarum clam were significantly attenuated especially against virus and bacteria. Of the significantly up-regulated genes after 30-day exposure, coleoptericin gene continuously kept a significantly higher increment. Besides, sialic acid binding lectin gene was similarly significantly up-regulated. It is a defense related protein in mollusc with affinity for bacterial lipopolysaccharide and facilitates their phagocytic uptake (Tunkijjanukij and Olafsen, 1998). The significant up-regulation of these immune-related genes implied that long-term exposure of ammonia nitrogen would increase the opportunities of $R$. philippinarum to bacterial infection.

Secondly, ammonia nitrogen exposure might cause some disturbances in membrane stability of the clams. Significantly variations of gene expression in membrane (GO: 0016020) might affect the membrane integrity. Phospholipase A2 isozymes (PA3A/PA3B/PA5) are key enzymes for phospholipid hydrolysis and generate free arachidonic acids. It has been suggested as a potential mediator for phospholipidosis during lysosome dysfunction (Balsinde et al., 2002). The significant variation of phospholipase A2 isozymes (PA3A/PA3B/PA5) gene after ammonia nitrogen exposure would attribute to the reduced integrity of lysosome membrane which we found in the previous study (Cong et al., 2017).

Thirdly, ammonia nitrogen exposure would probably affect neurotransduction from several aspects. The significantly down-regulation of glutamine synthetase (GS) and glutaminase (GLS) genes involved in biosynthesis of amino acids would result in decreased contents of glutamate and branched chain amino acids. It is known that GS is exclusively located in astrocytes to synthesize glutamine from glutamate and ammonia (Jayakumar and Norenberg, 2016). GLS is a key enzyme in cancer cell metabolism, growth and proliferation by converting glutamine to glutamate (Xiang et al., 2015). And branched amino acids are proved to be involved in the process of glutamine formation to alleviate the toxicity of ammonia (Holecek, 2013). Therefore, the reduced expression of glutamate and branched chain amino acid genes might both be involved in the detoxification of ammonia nitrogen. In addition, the significantly changed expression of many neuro-related genes would affect significantly the concentrations of neurotransmitters, including rabaptin, neural cell adhesion molecule, kappa-type opioid receptor, dopamine $\mathrm{N}$-acetyltransferase-like, neurogenic locus notch like protein, neurotransmitter transporter, 4-aminobutyrate aminotransferase, glutaminase, transglutaminase, dopamine N-acetyltransferase-like, metabotropic glutamate receptor 7 and so on. Rabaptins are a family of proteins involved in EGF receptor-mediated signal transduction during endocytosis (Barbieri et al., 2004; Disanza et al., 2009). Neural cell adhesion molecule is a kind of membrane glycoprotein which acts as a ligand in adhesion among neural cell bodies or neurites (Sadoul et al., 1983). Kappa-type opioid receptor is reported to be involved in signal transduction in central nervous system (Rácz and Halasy, 2002). Dopamine N-acetyltransferase-like is a kind of $\mathrm{N}$-acetyltransferase to catalyze the $\mathrm{N}$-acetylation of dopamine into $\mathrm{N}$ - 
acetyldopamine, which is the major precursor for quinone and subsequent pigment (Noh et al., 2016). 4-aminobutyrate aminotransferase (ABAT) catalyzes the first step of the principal inhibitory neurotransmitter $\gamma$-aminobytyric acid (GABA) to degrade within the mitochondrial matrix (Iftikhar et al., 2017). Moreover, GABA has been implicated in modulating the opioid mechanisms. For example morphine and beta-endorphin administration increases GABA levels in the globus pallidus and naloxone, at high dosages, acts as a GABA blocker (Stella et al., 2005). Significant variations of these genes suggested that neuro-signal transduction was obviously changed after the short-/longterm exposure of ammonia nitrogen.

Fourthly, ammonia nitrogen exposure would lead to some kind of tumor through several pathways. In previous study, we found some xenobiotic substances in the gill tissue after ammonia nitrogen exposure. It probably signified some kind of tumor. Although the mechanism of tumor formation has not been well elucidated, tumor has been found in invertebrate animals (Domazet-Lošo et al., 2014; Muehlenbachs et al., 2015) with similar transcriptome shifts of genes in vertebrate, affecting cell cycle, apoptosis, genomic stability and metabolism (Domazet-Lošo et al., 2014). In the present study, we also found alterations of gene expression involved in apoptosis and genomic stability. There were 7 overexpressed binding-related protein genes significantly up-regulated after 1-day exposure, including EGFL, SRP, SVEP, SRPX2, cbEGF, fibulin $1 / 2$ and NOTCH2 (Table 4). It is known that calcium is an essential element for the cells to function correctly, and its concentration is maintained within a narrow range. Additional calcium influx was approved to induce cell death by activating $\mathrm{Ca}^{2+}$. dependent enzymes, after NMDA-receptors were activated by ammonia nitrogen (Randall and Tsui, 2002). All of the 7 binding-related genes were found to contain EGF domain (Weinmaster et al., 1992; Knott et al., 1996), which were responsible for the high-affinity calcium binding (Selander-Sunnerhagen et al., 1992). EGF was proved to activate calcium signaling in vertebrate tumor cells (Bryant et al., 2004). So the 7 overexpressed calcium-binding protein genes were anticipated to take part in stress-related responses especially apoptosis after ammonia nitrogen exposure. Besides, there were two apoptosis inhibitors significantly down-regulated after 30-day exposure. The decrement of apoptosis inhibitor 1 and 2 would help to change the fate of cell death after ammonia nitrogen. Meanwhile, three genes responsible for DNA stability were found to be significantly changed their expressions after ammonia exposure. From Table 4, it can be seen that the expression level of PIF1-like helicase gene was significantly decreased and two DNA repair protein (XRCC4 and Ercc1) genes were significantly increased after one-day exposure. PIF1-like helicase is a conserved DNA helicase in organisms to keep the maintenance of genomic stability (Boulé and Zakian, 2006). XRCC4 and Ercc1 were responsible for repair of DNA double-strand break. Significant variations of the three genes suggested that genome of the clams were not stable after ammonia nitrogen exposure. It may be a hallmark of tumor formation like that in vertebrate (Domazet-Lošo et al., 2014). However, detailed mechanisms of these genes contribute to the formation of the tumor-like substances in clam requires more effort in the future.

In another aspect, KEGG enrichment analysis pointed out the key pathways affected by ammonia nitrogen exposure. Simply, 1-day exposure of ammonia nitrogen caused DEGs significantly enriched in four pathways, including Dorso-ventral axis formation, Notch signaling pathway, Thyroid hormone signaling pathway, Protein processing in endoplasmic reticulum (ER). According to the KEGG description, the first three pathways were all related to cancer formation. It seemed that short time (1 day) of ammonia stress of low concentration $(0.1 \mathrm{mg} / \mathrm{ml})$ was toxic enough to interfere with hormone signal and trigger cancer reaction of clam $R$. philippinarum. And turbulence in the fourth pathway would promise mistake in protein folding and induce ER stress to the gill tissue. After a long term (30 day) exposure of ammonia nitrogen, seven KEGG pathways were detected to enrich significantly. Three of the enriched KEGG pathways were involved in the immune response against pathogen infection, including the phagosome (ko04145), gap junction (ko04540) and pathogenic Escherichia coli infection (ko05130) pathways. Two of the enriched KEGG terms were responsible for fat and oil digestion and cancer development, including bile secretion (ko04976) and $\mathrm{ABC}$ transporters (ko02010) pathways. The rest two enriched KEGG pathways were involved in the metabolisms of carbohydrate and amino acids, including arginine biosynthesis (ko00220), alanine, aspartate and glutamate metabolism (ko00250). So the analysis of enriched KEGG pathway indicated that a long-term exposure of ammonia exposure would significantly change the metabolisms of lipid, carbohydrate and amino acid, and affect the immune system of clam to increase the opportunities of pathogen infection and cancer formation.

Therefore, it can be seen that ammonia nitrogen exposure disturbed the expression of genes in quite a few of pathways, and genes in different pathways might work together leading to a certain kind of toxicological endpoint. The present study provides a backbone description of gene and pathway responses towards ammonia nitrogen. Further study will be laid on the correlation of certain genes expression, protein function and its cellular location with a specific toxicological effect.

\section{Conclusion}

The present research provided the analysis for the molecular identification of key genes and main metabolic pathways of clam $R$. philippinarum under short- and long-term exposures of ammonia nitrogen at transcriptome level. Digital gene expression analysis in the gills revealed 90 significant DEGs under a short duration period and 161 significant DEGs under a long duration period. No significantly enriched GO terms were found in the short-term and the long-term exposure groups compared with the blank group. KEGG pathway analysis of DEGs indicated that short duration of ammonia exposure affected the Dorso-ventral axis formation, Notch signaling pathway, thyroid hormone signaling pathway and protein processing in endoplasmic reticulum pathway. The 30-day exposure led to DEGs significantly enriched in gap junction, immunity, signal and hormone transduction, as well as key substance metabolism. Functional research of significantly changed DEGs suggested that toxic effects of ammonia nitrogen on $R$. philippinarum clam was correlated with quite a few of pathways and mainly concerned with response to stimulus, binding and transporting of calcium ion, immune response, neuro-transduction, and metabolism of important substances such as fatty acid, protein, nucleotide acids and carbohydrate. The present study might provide a preliminary genetic mechanism about the detectable toxicological endpoints in previous study.

\section{Funding}

This study was funded by Natural Science Foundation of China (41406132), a Key Project from National Key Basic Research Program of China (2015CB453303) and a grant of "Youth Innovation Promotion Association CAS".

\section{Conflict of interest}

The authors declare that they have no conflict of interest.

\section{Ethical approval}

All applicable international, national, and/or institutional guidelines for the care and use of animals were followed.

\section{References}

Ślebioda, T.J., Kmieć, Z., 2014. Tumour necrosis factor superfamily members in the pathogenesis of inflammatory bowel disease. Mediat. Inflamm 2014, 15. http://dx.doi. org/10.1155/2014/325129. (Article ID 325129). 
Šedý, J., Bekiaris, V., Ware, C.F., 2015. Tumor necrosis factor superfamily in innate immunity and inflammation. CSH Perspect. Biol. 7, a016279. http://dx.doi.org/10. 1101/cshperspect.a016279.

Aguirre-Martínez, G.V., Buratti, S., Fabbri, E., Del Valls, A.T., Martín-Díaz, M.L., 2013. Using lysosomal membrane stability of haemocytes in Ruditapes philippinarum as a biomarker of cellular stress to assess contamination by caffeine, ibuprofen, carbamazepine and novobiocin. J. Environ. Sci.-China 25, 1408-1418. http://dx.doi.org/ 10.1016/S1001-0742(12)60207-1.

Armstrong, B.M., Lazorchak, J.M., Murphy, Cl.A., Haring, H.J., Jensen, K.M., Smith, M.E., 2012. Determining the effects of ammonia on fathead minnow (Pimephales promelas) reproduction. Sci. Total. Environ. 420, 127-133. http://dx.doi.org/10.1016/j. scitotenv.2012.01.005.

Arthur, J.W., West, C.W., Allen, K.N., Hedtke, S.F., 1987. Seasonal toxicity of ammonia to five fish and nine invertebrate species. Bull. Environ. Contam. Toxicol. 38, 324-331. http://dx.doi.org/10.1007/BF01606682.

Balsinde, J., Winstead, M.V., Dennis, E.A., 2002. Phospholipase A2 regulation of arachidonic acid mobilization. FEBS Lett. 531, 2-6. http://dx.doi.org/10.1016/S0014 5793(02)03413-0.

Barbieri, M.A., Fernandez-Pol, S., Hunker, C., Horazdovsky, B.H., Stahl, P.D., 2004. Role of Rab5 in EGF receptor-mediated signal transduction. Eur. J. Cell Biol. 83, 305-314. http://dx.doi.org/10.1078/0171-9335-00381.

Boulé, J.-B., Zakian, V.A., 2006. Roles of Pif1-like helicases in the maintenance of genomic stability. Nucleic Acids Res. 34, 4147-4153. http://dx.doi.org/10.1093/ nar/gkl561.

Bryant, J.A., Finn, R.S., Slamon, D.J., Cloughesy, T.F., Charles, A.C., 2004. EGF activates intracellular and intercellular calcium signaling by distinct pathways in tumor cells. Cancer Biol. Ther. 3, 1243-1249. http://dx.doi.org/10.4161/cbt.3.12.1233.

Cong, M., Wu, H., Yang, H., Zhao, J., Lv, J., 2017. Gill damage and neurotoxicity of ammonia nitrogen on the clam Ruditapes philippinarum. Ecotoxicology 26, 459-469. http://dx.doi.org/10.1007/s10646-017-1777-4.

Disanza, A., Frittoli, E., Palamidessi, A., Scita, G., 2009. Endocytosis and spatial restric tion of cell signaling. Mol. Oncol. 3, 280-296. http://dx.doi.org/10.1016/j.molonc 2009.05.008.

Domazet-Lošo, T., Klimovich, A., Anokhin, B., Anton-Erxleben, F., Hamm, M.J., Lange, C., Bosch, T.C.G., 2014. Naturally occurring tumours in the basal metazoan Hydra. Nat. Commun. 5, 4222. http://dx.doi.org/10.1038/ncomms5222.

Emmerson, K., Russo, R.C., Lund, R.E., Thurston, R.V., 1975. Aqueous ammonia equilibrium calculations: effects of pH and temperature. J. Fish Res. Board Can. 32, 2379-2383.

Holecek, M., 2013. Branched-chain amino acids and ammonia metabolism in liver disease: therapeutic implications. Nutrition 29, 1186-1191. http://dx.doi.org/10.1016/ j.nut.2013.01.022.

Hu, F., Pan, L., Cai, Y., Liu, T., Jin, Q., 2015. Deep sequencing of the scallop Chlamys farreri transcriptome response to tetrabromobisphenol A (TBBPA) stress. Mar. Genom. 19, 31-38. http://dx.doi.org/10.1016/j.margen.2014.09.004.

Huang, Q., Dong, S., Fang, C., Wu, X., Ye, T., Lin, Y., 2012. Deep sequencing-based transcriptome profiling analysis of exposed to PFOS. Aquat. Toxicol. 120, 54-58. http://dx doi.org/10.1016/j. aquatox.2012.04.013.

Iftikhar, H., Batool, S., Deep, A., Narasiman, B., Sharma, P.C., Malhotra, M., 2017. In silico analysis of the inhibitory activities of GABA derivatives on 4-aminobutyrate transaminase. Arab. J. Chem. 10, S1267-1275. http://dx.doi.org/10.1016/j.arabjc 2013.03.007.

Jayakumar, A.R., Norenberg, M.D., 2016. Glutamine Synthetase: Role in Neurological Disorders//The Glutamate/GABA-Glutamine Cycle. Springer International Publishing, pp. pp 327-350.

Kanehisa, M., Araki, M., Goto, S., Hattori, M., Hirakawa, M., Itoh, M., Katayama, T., Kawashima, S., Okuda, S., Tokimatsu, T., Yamanishi, Y., 2008. KEGG for linking genomes to life and the environment. Nucleic. Acids Res. 36, D480-D484. http://dx. doi.org/10.1093/nar/gkm882.

Keppler, C.J., 2007. Effects of ammonia on cellular biomarker responses in oysters (Crassostrea virginica). Bull. Environ. Contam. Toxicol. 78, 63-66. http://dx.doi.org/ 10.1007/s00128-007-9007-z.

Knott, V., Downing, K.A., Cardy, C.M., Handford, P., 1996. Calcium binding properties of an epidermal growth factor-like domain pair from human Fibrillin-1. J. Mol. Biol. 255, 22-27. http://dx.doi.org/10.1006/jmbi.1996.0003.

Li, B., Dewey, C., 2011. RSEM: accurate transcript quantification from RNA-Seq data with or without a reference genome. B.M.C. Bioinformatics 12, 323. http://dx.doi.org/10. 1186/1471-2105-12-323.

Livak, K.J., Schmittgen, T.D., 2001. Analysis of relative gene expression data using realtime quantitative PCR and the 2(-Delta DeltaC (T)) method. Methods 25, 402-408. http://dx.doi.org/10.1006/meth.2001.1262.

Maas, A., Seibel, B.A., Walsh, P.J., 2012. Effects of elevated ammonia concentrations on survival, metabolicrates, and glutamine synthetase activity in the Antarctic pteropod mollusk Clionelimacina Antarctica. Polar Biol. 35, 1123-1128. http://dx.doi.org/10. 1007/s00300-012-1158-7

Mao, X., Cai, T., Olyarchuk, J.G., Wei, L., 2005. Automated genome annotation and pathway identification using the KEGG Orthology (KO) as a controlled vocabulary. Bioinformatics 21, 3787-3793. http://dx.doi.org/10.1093/bioinformatics/bti430.

Muehlenbachs, A., Bhatnagar, J., Agudelo, C.A., Hidron, A., Eberhard, M.L., Mathison, B.A., Frace, M.A., Ito, A., Metcalfe, M.G., Rollin, D.C., Visvesvara, G.S., Pham, C.D., Jones, T.L., Greer, P.W., Vélez Hoyos, A., Olson, P.D., Diazgranados, L.R., Zaki, S.R., 2015. Malignant transformation of Hymenolepis nana in a human host. N. Engl. J. Med. 373, 1845-1852. http://dx.doi.org/10.1056/NEJMoa1505892.

Ngo, H.T., Wang, H.-N., Burke, T., Woods, C., Ginsburg, G.S., Vo-Dinh, T., 2015. Multiplex DNA biosensor for viral infection diagnosis using SERS molecular sentinelon-Chip. In: Toi, V., Lien Phuong, T. (Eds.), 5th International Conference on Biomedical Engineering in Vietnam. IFMBE Proceedings. Springer Cham. pp. 46 http://dx.doi.org/10.1007/978-3-319-11776-8_4.

Noh, M.Y., Koo, B., Kramer, K.J., Muthukrishnan, S., Arakane, Y., 2016. Arylalkylamine $\mathrm{N}$-acetyltransferase 1 gene (TcAANAT1) is required for cuticle morphology and pigmentation of the adult red flour beetle, Tribolium castaneum. Insect Biochem. Molec. 79, 119-129. http://dx.doi.org/10.1016/j.ibmb.2016.10.013.

Ponprateep, S., Vatanavicharn, T., Lo, C.F., Tassanakajon, A., Rimphanitchayakit, V., 2017. Alpha-2-macroglobulin is a modulator of prophenoloxidase system in pacific white shrimp Litopenaeus vannamai. Fish Shellfish Immun. 62, 68-74. http://dx.doi. org/10.1016/j.fsi.2016.12.028.

Rácz, B., Halasy, K., 2002. Kappa opioid receptor is expressed by somatostatin-and neuropeptide Y-containing interneurons in the rat hippocampus. Brain Res. 931, 50-55. http://dx.doi.org/10.1016/S0006-8993(02)02259-X.

Randall, D.J., Tsui, T.K.N., 2002. Ammonia toxicity in fish. Mar. Pollut. Bull. 45, 17-23. http://dx doi.org/10.1016/S0025-326X(02)00227-8.

Sadoul, R., Hirn, M., Deagostini-Bazin, H., Rougon, G., Goridis, C., 1983. Adult and embryonic mouse neural cell adhesion molecules have different binding properties. Nature 304, 347-349. http://dx.doi.org/10.1038/304347a0.

Sancho, D., Mourão-Sá, D., Joffre, O.P., Schulz, O., Rogers, N.C., Pennington, D.J., Carlyle, J.R., e Sousa, C.R., 2008. Tumor therapy in mice via antigen targeting to a novel, DC-restricted C-type lectin. J. Clin. Invest. 118, 2098-2110. http://dx.doi.org/ $10.1172 / \mathrm{JCI} 34584$.

Selander-Sunnerhagen, M., Ullner, M., Persson, E., Teleman, O., Stenflo, J., Drakenberg, T., 1992. How an epidermal growth factor (EGF)-like domain binds calcium. High resolution NMR structure of the calcium form of the $\mathrm{NH}_{2}$-terminal EGF-like domain in coagulation factor X. J. Biol. Chem. 267, 19642-19649.

Shatney, C.H., Benner, C., 1985. Sequential serum complement (C3) and immunoglobulin levels in shock/trauma patients developing acute fulminant systemic sepsis. Circ. Shock 16, 9-17.

Smart, G.R., 1978. Investigations of the toxic mechanisms of ammonia to fish-gas exchange in rainbow trout (Salmo gairdneri) exposed to acutely lethal concentrations. J. Fish Biol. 12, 93-104. http://dx.doi.org/10.1111/j.1095-8649.1978.tb04155.x.

Stella, L., D'ambra, C., Mazzeo, F., Capuano, A., Del Franco, F., Avolio, A., Ambrosino, F., 2005. Naltrexone plus benzodiazepine aids abstinence in opioid-dependent patients. Life Sci. 77, 2717-2722. http://dx.doi.org/10.1016/j.lfs.2005.05.036.

Tunkijjanukij, S., Olafsen, J.A., 1998. Sialic acid-binding lectin with antibacterial activity from the horse mussel: further characterization and immunolocalization. Dev. Comp. Immunol. 22, 139-150. http://dx.doi.org/10.1016/S0145-305X(98)00017-2.

Wang, X., Wang, L., Yao, C., Qiu, L., Zhang, H., Zhou, Z., Song, L., 2012. Alternation of immune parameters and cellular energy allocation of Chlamys farreri under ammoniaN exposure and Vibrio anguillarum challenge. Fish Shellfish Immunol. 32, 741-749. http://dx.doi.org/10.1016/j.fsi.2012.01.025.

Weinmaster, G., Roberts, V.J., Lemke, G., 1992. Notch2: a second mammalian Notch gene. Development 116, 931-941.

Widman, J., Meseck, S., Sennefelder, G., Veilleux, D., 2008. Toxicity of un-ionized ammonia, nitrite, and nitrate to juvenile bay scallops, Argopecten irradianss. Arch. Environ. Con. Tox. 54, 460-465. http://dx.doi.org/10.1007/s00244-007-9051-Z.

Xiang, Y., Stine, Z.E., Xia, J., Lu, Y., O’Connor, R.S., Altman, B.J., Hsieh, A.L., Gouw, A.M., Thomas, A.G., Gao, P., Sun, L., Song, L., Yan, B., Slusher, B.S., Zhuo, J., Ooi, L.L., Mancuso, A., Lee, C.G.L., McCallion, A.S., Le, A., Milone, M.C., Rayport, S., Felsher, D.W., Dang, C.V., 2015. Targeted inhibition of tumor-specific glutaminase diminishes cell-autonomous tumorigenesis. J. Clin. Invest. 125, 2293-2306. http:// dx.doi.org/10.1172/JCI75836.

Young, M.D., Wakefield, M.J., Smyth, G.K., Oshlack, A., 2010. Gene ontology analysis for RNA-seq: accounting for selection bias. Genome Biol. 11, R4. http://dx.doi.org/10. 1186/gb-2010-11-2-r14.

Zhao, X., Yu, H., Kong, L., Li, Q., 2012. Transcriptomic responses to salinity stress in the Pacific oyster Crassostrea gigas. PLoS One 7, e46244. http://dx.doi.org/10.1371/ journal.pone.0046244.

Zhu, J.Y., Wu, G.X., Zhang, Z., 2014. Upregulation of coleoptericin transcription in Tenebrio molitor parasitized by Scleroderma guan. J. Asia-Pac. Entomol. 17, 339-342. http://dx.doi.org/10.1016/j.aspen.2014.03.001. 